\title{
KNOWLEDGE, ATTITUDE AND PRACTICES OF DIABETIC RETINOPATHY AMONG DIABETICS IN GOA MEDICAL COLLEGE AND HOSPITAL
}

\author{
Adithya Phadnis ${ }^{1}$, Ugam P. S. Usgaonkar2, Sharvani Pai ${ }^{3}$ \\ 1 Junior Resident, Department of Ophthalmology, Goa Medical College and Hospital, Bambolim, Goa, India. \\ 2 Professor and HOD, Department of Ophthalmology, Goa Medical College and Hospital, Bambolim, Goa, India. \\ 3 Junior Resident, Department of Ophthalmology, Goa Medical College and Hospital, Bambolim, Goa, India.
}

\section{BACKGROUND}

ABSTRACT

Diabetes mellitus is currently a major disease of concern in terms of public health. It is reported to be affecting a population of more than 170 million globally and this number is expected to double between 2000 and 2030. 34.6\% of all diabetics developed some form of diabetic retinopathy. In the Indian subcontinent, the prevalence of diabetic retinopathy was found to be $18 \%$. Tight glycaemic control and regular screening can slow down the progression of diabetic retinopathy. Positive consciousness of retinopathy among individuals with diabetes could help in the timely identification and treatment of retinopathy.

Therefore, this study was conducted to assess knowledge, attitude and practice regarding diabetic retinopathy among the diabetic patients attending Ophthalmology OPD in Goa Medical College.

\section{MATERIALS AND METHODS}

This was a cross-sectional prospective study conducted among diabetic patients attending Ophthalmology OPD. Data was collected from 455 cases by convenient sampling method after taking their informed consent using a pretested structured questionnaire.

\begin{abstract}
RESULTS
Among the 455 diabetic patients who participated in the study, $63.7 \%$ were males. $49.8 \%$ were above 60 years of age. $52.7 \%$ were diabetic since 6 - 9 years. $67 \%$ had higher than primary education. $78 \%$ respondents were aware that diabetes could affect eyes. $33.4 \%$ believed that only medication was available to treat diabetic retinopathy. $25 \%$ were aware about LASER as a modality of treatment. 57.1\% would report to an ophthalmologist in the event of an eye problem. $67 \%$ opined that a person with diabetes should visit an Ophthalmologist even if his diabetes is under control. $66.1 \%$ believed that timely treatment can prevent damage due to diabetes in eyes. $48.3 \%$ followed up annually for an eye examination.
\end{abstract}

\section{CONCLUSION}

This study concludes that although there is a high level of knowledge about diabetic retinopathy, compliance in terms of annual routine eye examination is low. Action needs to be taken to identify the barriers in eye care seeking practices among the diabetics and bridge the gap between knowledge and practice by individual.

\section{KEY WORDS}

Diabetes Mellitus, Diabetic Retinopathy, KAP, Screening.

HOW TO CITE THIS ARTICLE: Phadnis A, Usgaonkar UPS, Pai S. Knowledge, attitude and practices of diabetic retinopathy among diabetics in Goa medical college and hospital. J. Evolution Med. Dent. Sci. 2018;7(38):4134-4136, D0I: 10.14260/jemds/2018/925

\section{BACKGROUND}

Diabetes mellitus is a non-communicable disease and currently a major disease of concern in terms of public health. It is reported to be affecting a population of more than 170 million globally and this number is expected to approximately double between 2000 and 2030.[1] In 2000, India had the highest number of diabetic people in the world (31.7 million).[2] Diabetic retinopathy is a serious microvascular complication of diabetes, which can lead to irreversible blindness. $34.6 \%$ of all diabetics developed some form of diabetic retinopathy.[3] In the Indian subcontinent, the prevalence of diabetic retinopathy was found to be $18 \% \cdot{ }^{[4]}$

'Financial or Other Competing Interest': None.

Submission 07-05-2018, Peer Review 23-06-2018,

Acceptance 01-07-2018, Published 17-09-2018.

Corresponding Author:

Dr. Sharvani Pai,

2A, Suvidha Apartments,

Road Lane No. 7, La-Campala Colony,

Miramar, Panaji-403001, Goa.

E-mail: sharvani.g.pai@gmail.com

DOI: $10.14260 /$ jemds $/ 2018 / 925$
A large percentage of diabetics present with advanced diabetic eye disease due to the silent nature of the disease. Thus, tight glycaemic control and regular screening can slow down the progression of diabetic retinopathy. Positive consciousness of retinopathy among individuals with diabetes could help in the timely identification and treatment of retinopathy.

We lack data regarding current knowledge, attitude and practices of diabetic retinopathy among diabetics in Goa. Therefore, this study was conducted to assess knowledge, attitude and practice regarding diabetic retinopathy among the diabetic patients attending Ophthalmology OPD in Goa Medical College.

\section{MATERIALS AND METHODS}

A cross-sectional, prospective study was conducted among diabetic patients attending Ophthalmology OPD. Ethical clearance was obtained from Institutional Ethics Committee prior to beginning the study. Data was collected from 455 cases by convenient sampling method after taking their informed consent, using a pretested structured questionnaire over a period of 4 months (September 2017 to December 2017). The questionnaire had two parts. The first part had 
the basic information like gender, age, duration of diabetes and education, while the second part had questions regarding Knowledge, Attitude and Practice of Diabetic Retinopathy. Data was entered in MS Excel and results were expressed as percentages.

\section{RESULTS}

Among the 455 diabetic patients who participated in the study, $63.7 \%(n=290)$ were males and $36.2 \%(n=165)$ were females. $49.8 \%(n=227)$ were above 60 years of age. $52.7 \%$ $(n=240)$ were diabetic since $6-9$ years. 67\% $(n=305)$ had higher than primary education. The detailed characteristics of the study sample is shown in Table 1.

\section{Knowledge about Diabetic Retinopathy}

When asked if Diabetes Mellitus can cause eye disease, 78\% $(n=355)$ responded correctly that diabetes can affect eyes, while $22 \%(n=100)$ had no knowledge that diabetes could cause eye disease. Regarding knowledge of availability of treatment for diabetic retinopathy, 33.4\% ( $n=152)$ believed that only medications were available to treat diabetic retinopathy [Figure 1]. Patients were questioned on their choice of health professionals in the event of eye problem, to which majority $57.1 \%(n=260)$ replied saying they would report to an Ophthalmologist [Figure 2].

\section{Attitude towards Diabetic Retinopathy}

$67 \%(n=305)$ of the patients opined that a person with diabetes should visit an Ophthalmologist even if his diabetes is under control [Figure 3], while $66.1 \%(n=301)$ believed that timely treatment can prevent damage due to diabetes in eyes.

\section{Practice regarding Diabetic Retinopathy}

$48.3 \%(n=220)$ believed that an annual eye examination is mandatory in all diabetics [Figure 4].

\begin{tabular}{|c|c|c|c|}
\hline \multicolumn{2}{|r|}{ Variables } & $\mathbf{n}$ & $\%$ \\
\hline \multirow{2}{*}{ Gender } & Males & 290 & 63.7 \\
\hline & Females & 165 & 36.2 \\
\hline \multirow{4}{*}{$\begin{array}{c}\text { Age } \\
\text { (in years) }\end{array}$} & $<20$ & 2 & 0.4 \\
\hline & $21-39$ & 42 & 9.2 \\
\hline & $40-59$ & 184 & 40.4 \\
\hline & $>60$ & 227 & 49.8 \\
\hline \multirow{3}{*}{ Education } & Uneducated & 46 & 10.1 \\
\hline & Upto Primary & 104 & 22.8 \\
\hline & Higher than Primary & 305 & 67 \\
\hline \multirow{4}{*}{$\begin{array}{c}\text { Duration } \\
\text { of Diabetes } \\
\text { (in years) }\end{array}$} & $<5$ & 76 & 16.7 \\
\hline & $6-9$ & 240 & 52.7 \\
\hline & $9-14$ & 84 & 18.5 \\
\hline & $>15$ & 55 & 12 \\
\hline
\end{tabular}

Table 1. Showing Characteristics of the Study Sample

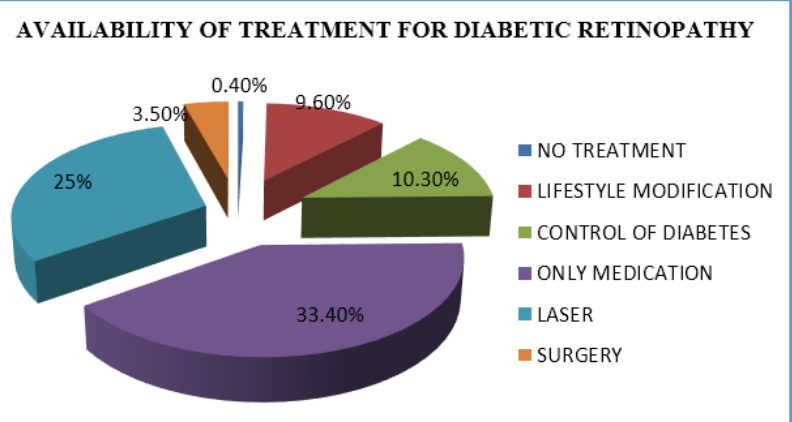

Figure 1. Knowledge of availability of treatment for Diabetic Retinopathy

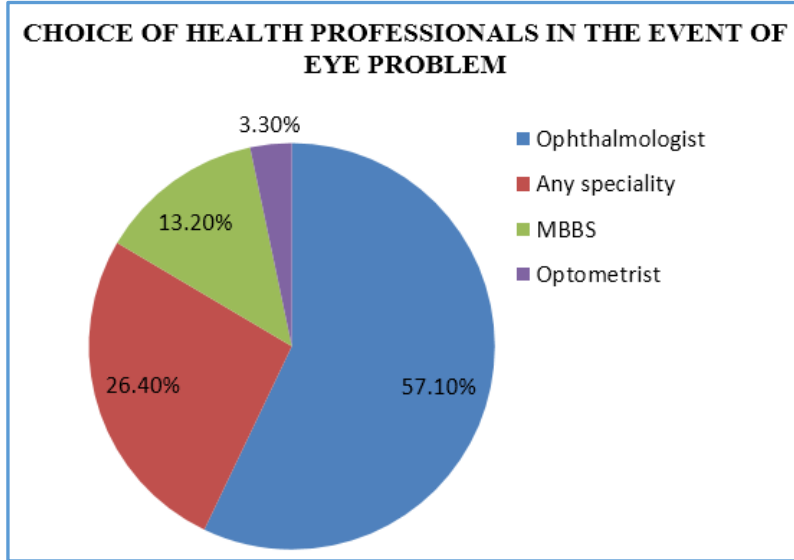

Figure 2. Knowledge regarding Choice of Health Professionals in the Event of Eye Problem

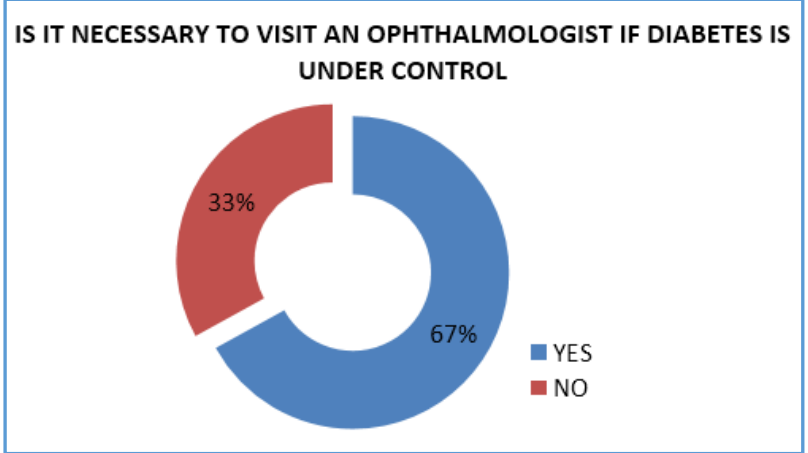

Figure 3. Is it necessary to visit an Ophthalmologist If Diabetes is Under Control?

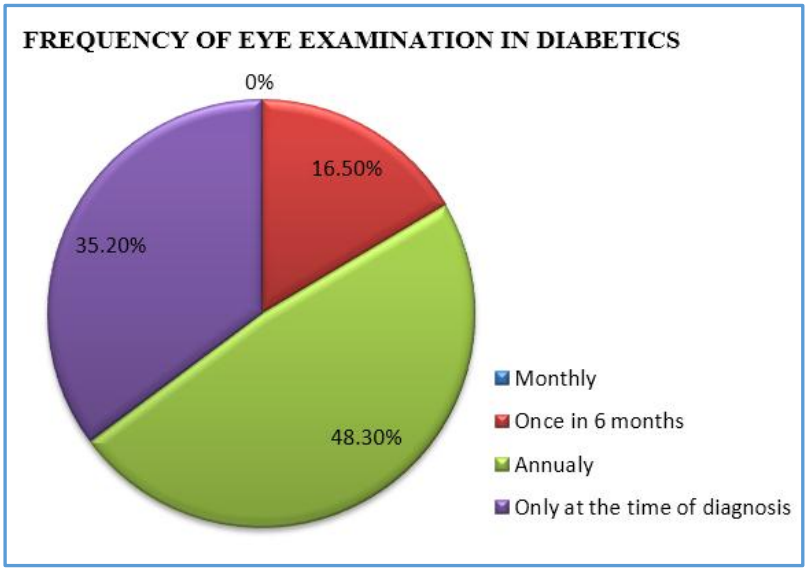

Figure 4. Frequency of Eye Examination in Diabetic Patients 


\section{DISCUSSION}

Majority (78\%) of the diabetics in the study had good knowledge that diabetes can cause eye disease, which could be related to the fact that $67 \%$ of the study sample had literacy levels of higher than primary education. These findings were comparable to a study conducted in North Jordan by Bakkar MM et al, which concluded that the main factor that was related to increased awareness of Diabetic Retinopathy was the level of education.[5] The high level of awareness among the study sample can also be related to majority of respondents $(n=379,83.3 \%)$ having diabetes for a duration of more than 5 years. A study conducted by Addoor KR et al stated that the patients with duration of diabetes more than 5 years were more aware of the consequences of diabetes.[6] However, our study being hospital based, results cannot be applied to general population.

Regarding knowledge of availability of treatment in Diabetic Retinopathy, $33.4 \%$ believed that only medication could treat diabetic retinopathy. $25 \%(n=114)$ were aware about LASER in the treatment of diabetic retinopathy. This is higher than study conducted by Shetgar AC et al, in a medical college in Karnataka, which showed that only $5.3 \%$ of individuals knew that LASER could treat Diabetic Retinopathy.[7]

$57.1 \%(n=260)$ of the respondents said that they would report to an Ophthalmologist in the event of an eye problem, while $26.4 \%(n=120)$ would report to any other speciality. This highlights the importance of awareness of Diabetic Retinopathy and its screening guidelines amongst all medical specialities, so that timely referral and early intervention can be done to prevent sight threatening disease. Since primary care physicians are the main source of information to patient, they play a major role when it comes to delivering the best standard of care to patients. [8]

More than half of the patients opined that a person with diabetes should visit an Ophthalmologist even if his diabetes is under control and timely treatment can prevent damage due to diabetes. However, only $48.3 \%$ of the patients followed up annually for a routine eye examination. Thus, despite the high level of awareness in this study, compliance in terms of routine eye examination seems to be low and further studies are required to identify patient related barriers in not getting a routine eye examination despite knowledge about the disease. Bakkar MM et al found that apart from lack of knowledge about diabetic retinopathy, lack of time, cost of test, fear of discovering something bad and living in remote areas were some of the barriers preventing patients from getting a routine eye examination. [5]

\section{CONCLUSION}

This study concludes that although there is a high level of knowledge about diabetic retinopathy, compliance in terms of annual routine eye examination is low. Further studies need to be undertaken to identify the barriers in eye care seeking practices among the diabetics and bridge the gap between knowledge and practice by an individual. Considering that the proportion of people suffering from diabetes and diabetic eye disease is expected to rise, routine eye screening is an important cost-effective strategy to prevent visual complications due to diabetes. Tailor made Information, Education and Communication (IEC) activities suitable to different group of population can be formulated.

\section{ACKNOWLEDGEMENTS}

We are indebted to optometry interns and OPD staff for their help in carrying out the survey.

\section{REFERENCES}

[1] Wild S, Roglic G, Green A, et al. Global prevalence of diabetes: estimates for the year 2000 and projections for 2030. Diabetes Care 2004;27(5):1047-53.

[2] Kaveeshwar SA, Cornwall J. The current state of diabetes mellitus in India. The Australasian Medical Journal 2014;7(1):45-8.

[3] Yau JWY, Rogers SL, Kawasaki R, et al. Global prevalence and major risk factors of diabetic retinopathy. Diabetes Care 2012;35(3):556-64.

[4] Raman R, Rani PK, Rachepalle RS, et al. Prevalence of diabetic retinopathy in India: Sankara Nethralaya Diabetic Retinopathy Epidemiology and Molecular Genetics Study Report 2. Ophthalmology 2009;116(2):311-8.

[5] Bakkar MM, Haddad MF, Gammoh YS. Awareness of diabetic retinopathy among patients with type 2 diabetes mellitus in Jordan. Diabetes, Metabolic Syndrome and Obesity: Targets and Therapy 2017;10:435-41.

[6] Addoor KR, Bhandary SV, Khanna R, et al. Assessment of awareness of diabetic retinopathy among the diabetics attending the peripheral diabetic clinics in Melaka, Malaysia. Med J Malaysia 2011;66(1):48-52.

[7] Shetgar AC, Patil B, Salagar MC, et al. Assessment of awareness of diabetic retinopathy among diabetics: a clinical survey. Indian Journal of Clinical and Experimental Ophthalmology 2015;1(4):260-3.

[8] Al Rasheed R, Al Adel F. Diabetic retinopathy: Knowledge, awareness and practices of physicians in primary-care centers in Riyadh, Saudi Arabia. Saudi Journal of Ophthalmology 2017;31(1):2-6. 